\title{
Use of sodium salt electrolysis in the process of continuous modification of eutectic EN AC-AISi 12 alloy
}

\author{
J PEZDA $^{1, *}$ and A BIALOBRZESKI ${ }^{2}$ \\ ${ }^{1}$ Faculty of Chipless Forming Technology, University of Bielsko-Biała, ul. Willowa 2, 43-309 Bielsko-Biała, Poland \\ ${ }^{2}$ Foundry Engineering Institute, Zakopiańska 73, 30-418 Kraków, Poland
}

MS received 10 April 2013; revised 14 February 2014

\begin{abstract}
This paper presents test results concerning the selection of sodium salt for the technology of continuous modification of the EN AC-AISi 12 alloy, which is based on electrolysis of sodium salts, occurring directly in a crucible with liquid alloy. Sodium ions formed as a result of the sodium salt dissociation and the electrolysis are 'transferred' through walls of the retort made of solid electrolyte. Upon contact with the liquid alloy, which functions as a cathode, sodium ions are transformed into the atomic state, modifying the alloy. As a measure of the alloy modification extent, the obtained increase of the tensile strength $R_{\mathrm{m}}$ and change of metallographic structure are used, confirming obtained modification effect of the investigated alloy.
\end{abstract}

Keywords. Aluminum alloy; modification; electrolysis; tensile strength.

\section{Introduction}

Silumins belong to the most common group of casting alloys. A broad application field of such alloys in various industries results from good casting and utility properties. These alloys are characterized by low density, relatively low melting temperature, good thermal and electric conductivity (good castability, low shrinkage) as well as good machinability and considerable corrosion resistance. In the case of such alloys, their structure and, more precisely, their size, shape and way of distribution of hard and brittle crystals of $\beta$ ( $\mathrm{Si}$ ) silicon in the plastic groundmass of the solid solution $\alpha$ (Al), have an effect on their mechanical properties.

For improving (modifying) the structure of these alloys, i.e., for achieving fragmentation of the structure, technological treatments are used, which involve these alloys being introduced with a small quantities of various metallic elements, known as modifiers, e.g., $\mathrm{Na}, \mathrm{Sb}, \mathrm{Sr}, \mathrm{P}, \mathrm{Ti}^{1-7}$ and rare earth elements. ${ }^{8,9}$

Modification of the alloy is aimed at improving its mechanical properties, such as elongation and impact strength.

Historically, sodium belongs to the oldest, the most commonly used within the industry, and the most effective modifiers for hypoeutectic and peritectic alloys. ${ }^{1,2,10,11}$ Such modifier is introduced into metal bath in a metallic form, or in the form of chemical compounds containing sodium.

Sodium inhibits nucleation of silicon crystals, which results in the occurrence of superfusion of eutectic crystallization, and transformation of an irregular lamellar eutectic mixture $\alpha+\beta$ into eutectic mixture having a fibrous structure, which is connected with a considerable reduction

\footnotetext{
*Author for correspondence (jpezda@ath.bielsko.pl)
}

of interfacial distance and distinct change of eutectic silicon crystals. However, regardless of the form in which the modifier is introduced to the metal bath, its action is relatively short, mainly due to evaporation from the metal bath, which from a technological point of view, constitutes its significant disadvantage. ${ }^{12}$

Introduction of continuous modification with sodium, which occurs directly in metal bath, with the use of continuous electrolysis of sodium compounds (salts), could be a solution to the problem connected with limited time of action of this modifier. For performing such process, it is necessary to use a solid electrolyte that conducts sodium ions (ionic conductance) and simultaneously maintains a solid state of aggregation at melting temperature and superheating temperature of the alloy. Such ceramic materials consist of sodium beta-alumina obtained with the use of the electro-ferritic method, which contains $90-95 \%$ of phase $\beta$ and about $0.5 \%$ $\mathrm{Na}_{2} \mathrm{AlO}_{2}$ stabilized with lithium, magnesium or zirconium, assuring conductance of sodium ions ${ }^{13,14}$ that arise as a result of dissociation and electrolysis, which in contact with liquid alloy, pass into atomic state, modifying the alloy. Products manufactured based on the beta-alumina are durable, semicrystallic ceramic materials, in which movable ions are $\mathrm{Na}^{+}$, $\mathrm{K}^{+}, \mathrm{Ag}^{+}, \mathrm{Cu}^{+}, \mathrm{Li}^{+}, \mathrm{Pb}^{2+}, \mathrm{Sr}^{2+}$ and $\mathrm{Ba}^{2+} .15,16$ The main area of their implementation is cells of heavy duty batteries based on the solid electrolyte ${ }^{17-21}$ and sensors of sodium. ${ }^{22-24}$

\section{Materials and methods}

The basis for the continuous modification process developed by Białobrzeski ${ }^{25}$ is the usage of sodium salt located in a retort manufactured from solid electrolyte, which, as a result 
of the applied d.c. voltage, undergoes dissociation followed by electrolysis.

As the material of anode (source of sodium ions) during the course of the testing, use is made of the salts comprising the following chemical compounds:

(1) salt $\mathbf{A}-\mathrm{NaNO}_{3}, \mathrm{Na}_{2} \mathrm{CO}_{3}$;

(2) salt $\mathbf{B}-\mathrm{NaNO}_{3}, \mathrm{NaCl}, \mathrm{Na}_{2} \mathrm{CO}_{3}$.

Liquid sodium salt (anode) positioned in the stop-ended retort, produced from the beta-alumina stabilized with zirconium (B2 type, with length of $220 \mathrm{~mm}$, internal diameter of $30 \mathrm{~mm}$ and wall thickness of 1-2 $\mathrm{mm}$ ), produced by British Company Ionotec Ltd., was connected with electric current generator via electrode. According to suggestions of this Company, the stop-ended tubes (retorts) from 'betaalumina' stabilized with zirconium (contents of about $6 \%$ $\mathrm{ZrO}_{2}$ ), conducting sodium ions, seem to be more suitable to operation in liquid aluminum alloys. In such case zirconium increases resistance of the ceramics for thermal shocks, which are unavoidable in conditions of planned experiment. It should be noticed that zirconium reduces conductivity of this ceramics only to a slight extent.

Specification of the retort used in course of the investigations is presented in table 1 .

Investigated alloy was melted in ceramic crucible in electric resistance furnace.

Melted EN AC-AlSi $1_{12}$ alloy was initially refined with use of Rafal 1 at a quantity of $0.4 \%$ mass of charge, and in the successive step, after removal of slag from the metal level; the liquid alloy was connected to the electric current generator with graphite electrode. The scheme of the test stand is presented in figure 1.

To initiate the heat-up of the retort, and also to restrict possibility of its damage during immersion in the liquid alloy, prior to commencing the electrolysis process, the ceramic

Table 1. Specification of the retort.

Property

Phase content, \% beta"

Porosity, \%

Maximum pore size, $\mu \mathrm{m}$

Maximum grain size, $\mu \mathrm{m}$

Bending strength, MPa

Strength Weibull factor

Fracture toughness, MPa $\mathrm{m}^{1 / 2}$

90-95

$1-2$

5

20

250-300

$8-13$

2-3

Property ionic conductivity $(\Omega \mathrm{cm})^{-1}$

$25^{\circ} \mathrm{C}$

0.002

$200^{\circ} \mathrm{C}$

0.092

$300^{\circ} \mathrm{C}$

0.24

$400^{\circ} \mathrm{C}$

0.38

Thermal expansion coefficient $\left(\times 10^{-6}\right)$

$0-500^{\circ} \mathrm{C}$

$500-1000^{\circ} \mathrm{C}$ retort filled with the salt was placed for a few minutes directly over the metal level of the alloy overheated to a temperature of $680-700^{\circ} \mathrm{C}$ (figure 2).

After immersing the retort filled with sodium in liquid alloy (figure 3) and when molten state was reached, the d.c. circuit was closed, stabilizing the current intensity at a constant level of $10 \mathrm{~A}$ for salt A and $5 \mathrm{~A}$ for salt $\mathrm{B}$.

Reduction of current intensity in case of salt B resulted from more rapid course of the electrolysis and fast depletion of the salt in the retort. Active surface area of the retort amounting to $163.8 \mathrm{~cm}^{2}$ was maintained at constant level though its immersing in the alloy to the depth of $160 \mathrm{~mm}$ (adjusted after each extraction of the alloy from the crucible). Voltage supply was accomplished with use of stabilized d.c. transistor-type power supply of $300 \mathrm{~W}$.

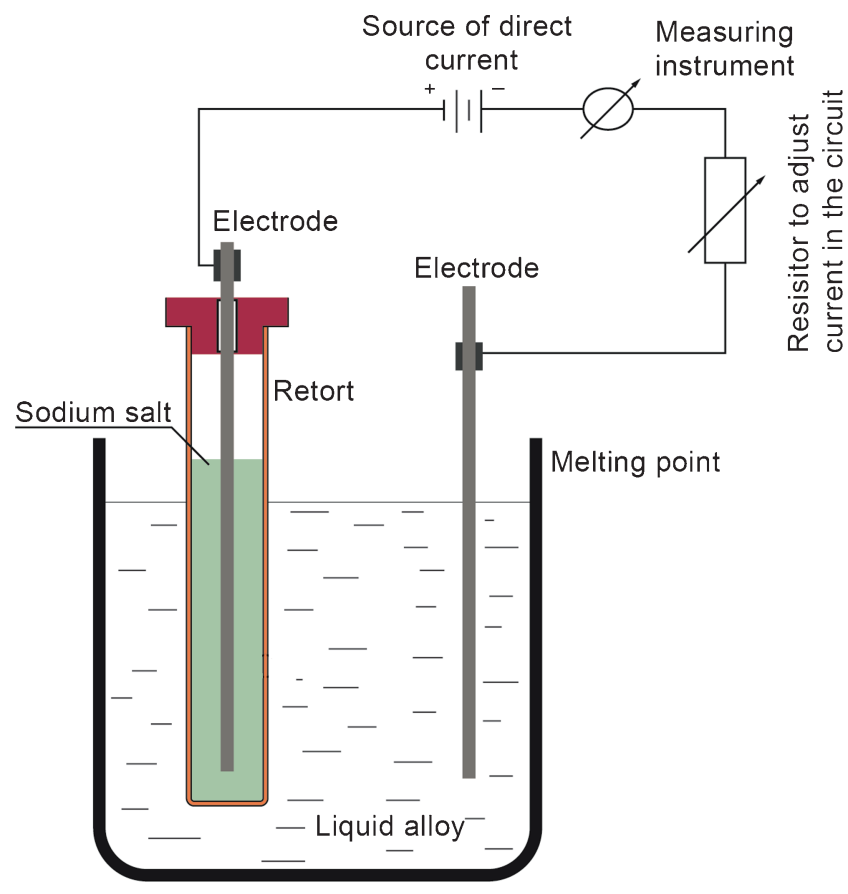

Figure 1. Scheme of the test stand.

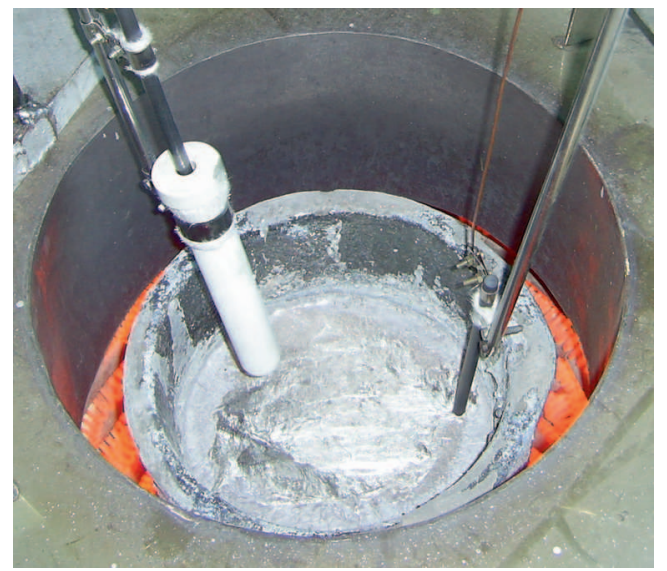

Figure 2. Initial heat-up of the retort over metal level of the alloy. 


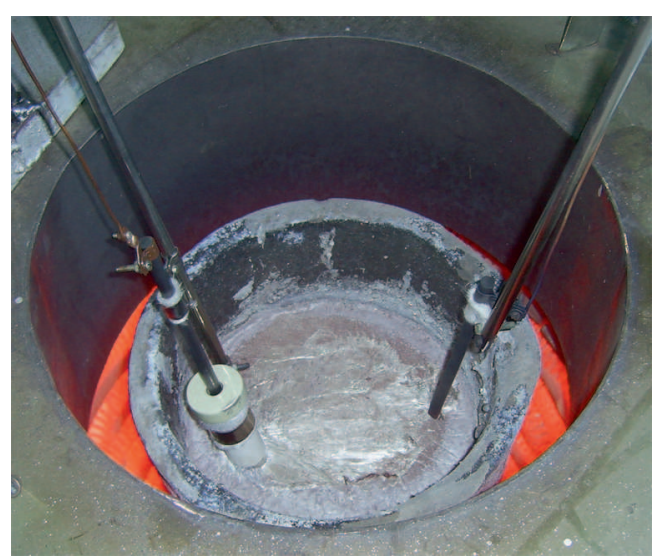

Figure 3. View of the test stand during the course of the electrolysis.

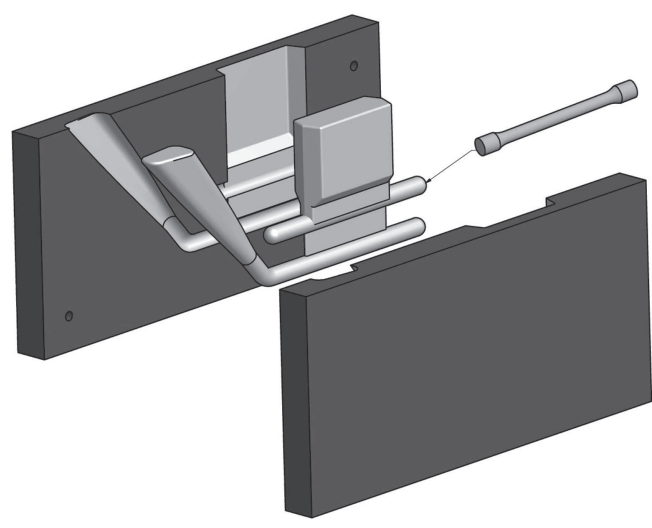

Figure 4. Mould to production of castings of the test pieces.

Current intensity for unit surface area amounted to $61 \mathrm{~mA} \mathrm{~cm}^{-2}$ for salt A and $30.5 \mathrm{~mA} \mathrm{~cm} \mathrm{~cm}^{-2}$ for salt B. Total time of the modification process amounted to $240 \mathrm{~min}$ for salt $\mathrm{A}$ and 160 min for salt $\mathrm{B}$ was directly connected with quantity of the salt decreasing together with elapsing time and quantity of the alloy in the crucible.

Casting of the test pieces at a quantity of three test pieces for each set were poured every $30 \mathrm{~min}$ in the case of salt A and every 10 min for salt B. The alloy was taken directly from the crucible and poured into metallic mould (figure 4) heated to temperature $220-250^{\circ} \mathrm{C}$, destined to production of standardized specimens to strength tests.

The tensile strength $R_{\mathrm{m}}$ was determined after performing the static tensile test on the ZD-20 tester according to the EN 10002-1:2001 standard.

\section{Results and discussion}

Among the modifiers, the $\mathrm{Na}, \mathrm{Sr}$ and $\mathrm{Sb}^{12,26,27}$ have found their practical application for hypo- and near eutectic silumins as a modifiers of long-lasting action having effect of change of morphology of $\mathrm{Si}$, and $\mathrm{Ti}$ and $\mathrm{B}$ having effect on the morphology of $\mathrm{Al}$ dendrites, while in case of

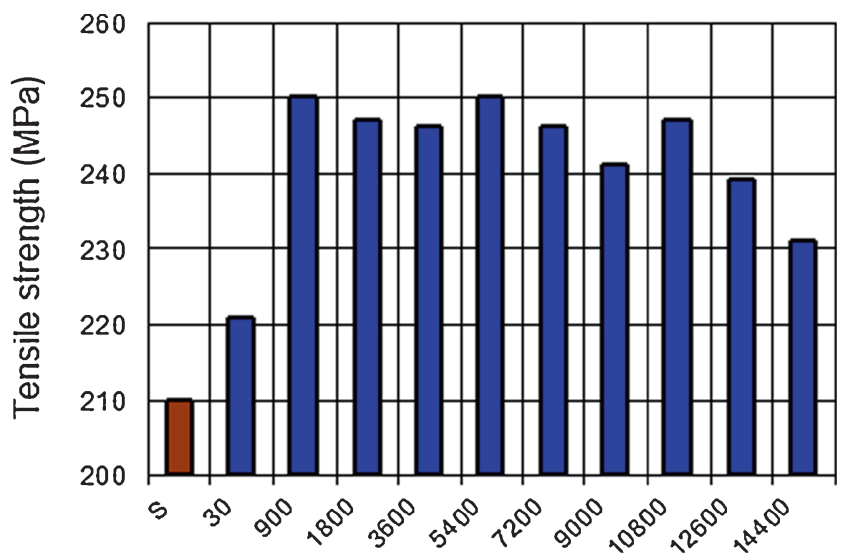

Figure 5. Change of the $R_{\mathrm{m}}$ of the investigated alloy during the course of continuous electrolysis of salt A.

hypereutectic silumins to the modifiers belong $\mathrm{P}, \mathrm{Bi}$ and Ti. Sodium is introduced into metal bath in metallic form or in form of chemical compounds containing sodium. Its effect consists mainly on the inhibition of nuclei of silicon crystals and transformation of irregular lamellar eutectic $\alpha+\beta$ into fibrous eutectic. ${ }^{11,12,28,29}$ In case of the modification consisting in adding sodium into the metal bath, transformation of sodium - in result of exchange reaction-from chemical compound AlP to $\mathrm{Na}_{3} \mathrm{P}$ was dealt. The compound $\mathrm{Na}_{3} \mathrm{P}$, not being a nucleus of crystallization, affects on overcooling of the bath and crystallization of the eutectic, leading to the generation of fine-grained structure of the alloy. ${ }^{30}$ Sodium can be introduced into metal bath in metallic form (vacuum melted metallic sodium NAVAC produced by Foseco Company ${ }^{31}$ or salt mixture comprising $(\mathrm{NaF}$-sodium fluoride, e.g., COVERAL produced by Foseco Company). Quantity of sodium necessary to the modification depends on the degree of contamination with phosphorus and contents of silicon. ${ }^{2,11}$ Additive in the range from a few to $100 \mathrm{ppm}$ of the $\mathrm{Sr}, \mathrm{Na}, \mathrm{Ca}, \mathrm{Ba}$ or $\mathrm{Eu}$ enables modification of the morphology of eutectic silicon, from thick lamellar precipitations to fine fibrous ones, what have beneficial effect both on strength and plasticity. ${ }^{32,33}$ Effect of the modification can be obtained, however, as early as with contents of $0.001 \%$ of metallic sodium and $0.005 \%$ of sodium salt relative to mass of the alloy, ${ }^{30}$ while they are added in order to obtain contents of sodium in the alloy from 0.005 to $0.015 \%$. Optimal strength parameters can be obtained even at small contents of sodium salt $(60 \% \mathrm{NaF}, 40 \% \mathrm{NaCl})$ amounted to $0.05-0.06 \%$ mass of the charge. ${ }^{34}$

Figure 5 presents a change of the tensile strength $R_{\mathrm{m}}$ during the course of continuous modification of the alloy with the use of salt A (the test piece marked with symbol ' $S$ ' denotes material in its initial state after performed the treatment of refinement).

There exists a distinct difference between the obtained tensile strength $R_{\mathrm{m}}$ of the refined alloy (test piece ' $\mathrm{S}$ 'figure 5) and the modified alloy with the use of electrolysis of salt A. After 15 min, since the beginning of the alloy 
modification, it has been noticed an increase of the tensile strength $R_{\mathrm{m}}(250 \mathrm{MPa})$. Lacking further increase of the strength $R_{\mathrm{m}}$ and/or its slight fluctuations result from changing extend of modification of the alloy, which depends directly on quantity of introduced sodium and simultaneous collection of the alloy from the crucible to production of specimens to the strength tests.

The current intensity during the process was maintained at a constant level of $5 \mathrm{~A}$ for $150 \mathrm{~min}$, while the total time of the modification process amounted to $240 \mathrm{~min}$.

After 150 min since the beginning of the electrolysis it has been observed a slight drop of the mechanical properties, as a result of loss of the salt in the retort resulting reduction of active surface of the retort, and hence, limitation of quantity of sodium introduced to the metal bath.

Figure 6 presents changes of the tensile strength $R_{\mathrm{m}}$ of the investigated alloy during the course of electrolysis of salt B.

In case of salt B, as early as after 10 min after beginning the electrolysis, it obtained an increase of the tensile strength $R_{\mathrm{m}}$ as compared with the refined alloy (test piece ' $\mathrm{S}$ '-figure 5). The maximal value of the tensile strength

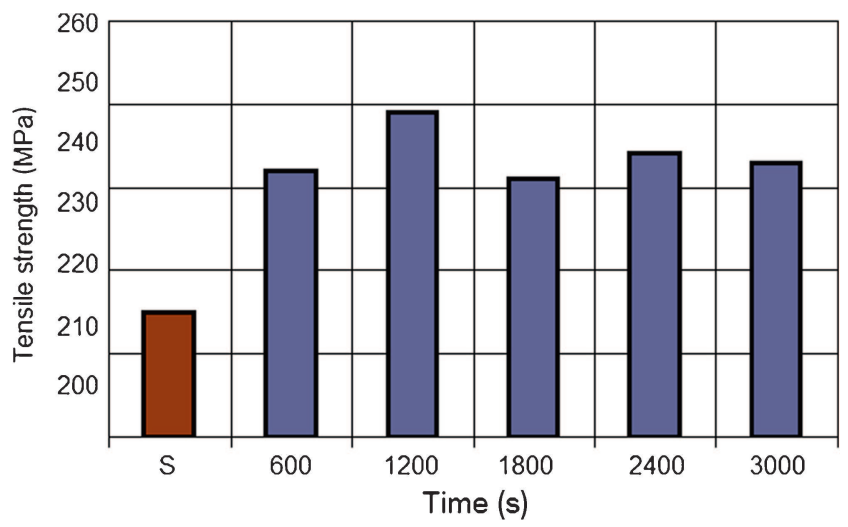

Figure 6. Change of the $R_{\mathrm{m}}$ investigated alloy during the course of electrolysis of salt B.

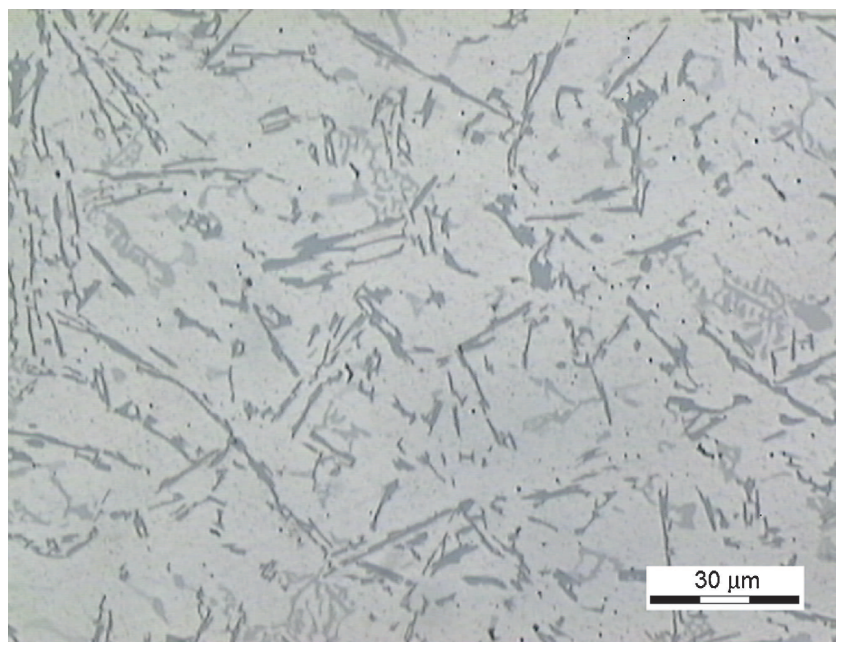

Figure 7. Metallographic structure of the EN AC-44200 alloy after refinement (initial alloy).
$R_{\mathrm{m}}(239 \mathrm{MPa})$ was obtained after $20 \mathrm{~min}$. Unfortunately, in the case of salt $\mathrm{B}$, there occurred the necessity of refilling the salt in the retort after $20 \mathrm{~min}$ of the electrolysis. The modification process was performed for a successive $30 \mathrm{~min}$ only, due to a rapidly consumed salt and instability of the process.

After complete process of the electrolysis, the retort was taken from the metal bath. Lack of cracks and damages on its surface suggests a possibility of its reuse. Positive results have been obtained.

The process of modification of near-eutectic silumin results in a change of its structure (refinement of the eutectic silicon). ${ }^{2,35}$ To confirm a possible change of the structure, photographs of microstructure of the refined alloy (initial alloy) and the alloy after 20 and 160 min after commencing electrolysis of salt A has been taken.

Figure 7 depicts photographs of metallographic structures of the investigated alloy before commencing the electrolysis of sodium salt.

The structure of the initial alloy prior to beginning the electrolysis can be characterized by distinct precipitations of
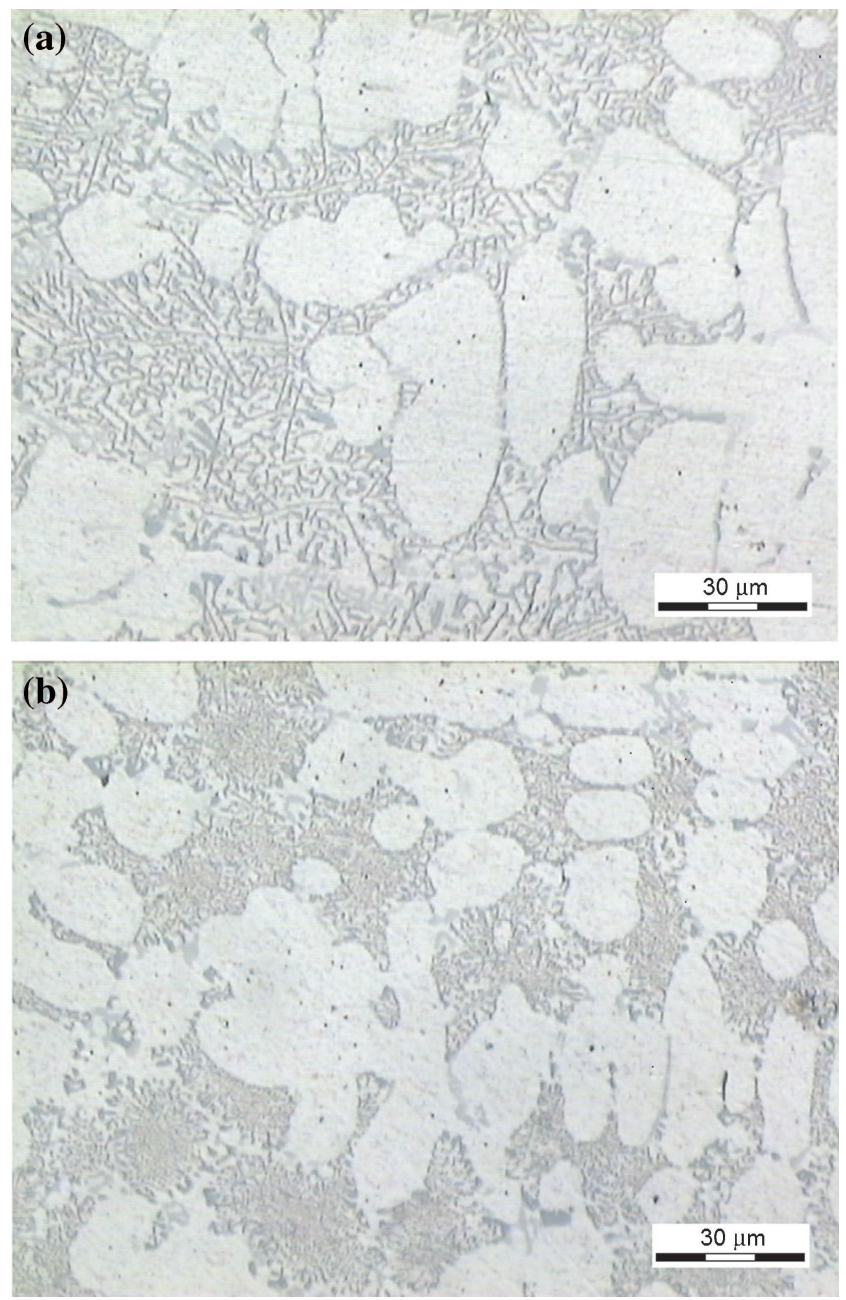

Figure 8. Microstructure of the EN AC-AlSi 12 alloy: (a) after $10 \mathrm{~min}$ of the electrolysis and (b) after $160 \mathrm{~min}$ of the electrolysis. 
the $\beta$ phase in the form of lamellar silicon, which is present in non-modified alloys. ${ }^{2,5,12}$

Figure 8 presents a structure of the alloy after $10 \mathrm{~min}$ (figure $8 \mathrm{a}$ ) and after $160 \mathrm{~min}$ of the performed process of the electrolysis (figure 8b).

The microstructure of the test piece poured after $10 \mathrm{~min}$ (figure 8a) is characterized by partially modified silicon in the eutectic mixture $\alpha+\beta$, which is the result of the commenced process of the modification. Dendritic precipitations of the phase $\alpha(\mathrm{Al})$ and the modified eutectic mixture $\alpha+\beta$ with fibrous form of eutectic silicon ${ }^{11,36}$ which is characteristic for the alloy after modification, ${ }^{12,37,38}$ are presented in figure $8 b$.

\section{Conclusion}

Confirmation of possibilities of implementation of sodium salt electrolysis in the process of continuous modification of silumins was the main objective of the presented work. The tensile strength $R_{\mathrm{m}}$ obtained in the course of the experiment as well as microstructure analysis unequivocally points at the conductance of sodium ions due to the solid electrolyte under physical-chemical conditions present during the modification of near-eutectic $\mathrm{EN} \mathrm{AC}-\mathrm{AlSi}_{12}$ alloy in laboratory conditions. The ternary salt 'A' with uncomplicated chemical composition has fulfilled requirements concerning the time of its acting and the effect of such acting in the form of the increased tensile strength $R_{\mathrm{m}}$. Further investigations aimed at optimization of electrolysis process parameters and selection of composition of the salts as an aspect of the process stabilization to obtain the required mechanical properties can constitute a starting point to implementation of the continuous modification of the sodium salt performed on an industrial scale.

\section{Acknowledgement}

The present work was performed within framework of Research Project no. 3 T08B 06329 financed by the State Committee for Scientific Research (MNiSW).

\section{References}

1. Pacz A 1921 US Patent No. 1387900

2. Pietrowski S 2001 Silumins (Łódź: Technical University Editorial) p 195

3. Fatahalla N, Hafiz M and Abdulkhalek M 1999 J. Mater. Sci. 343555

4. Nogita K and Dahle A K 2001 Mater. Trans. 42207

5. Hegde S and Prabhu K N 2008 J. Mater. Sci. 433009

6. Closset B and Gruzleski J E 1982 Metall. Trans. A 13945

7. Gilbert J and Rooy E L 2004 Aluminum alloy castings: properties, processes and applications $(\mathrm{OH}$, USA: ASM International) p 40
8. Nogita K, McDonald S D and Dahle A K 2004 Mater. Trans. 45323

9. Krupiński M, Labisz K, Dobrzański L A and Rdzawski Z 2010 Arch. Foundry Eng. 1079

10. Davis J R 1993 Aluminum and aluminum alloys (OH, USA: ASM International) p 223

11. Poniewierski Z 1989 Crystallization and properties of silumins (Warszawa: WNT) p 73

12. Wasilewski P 1993 Modification and its impact on structure and properties. Monography, solidification of metals and alloys (PAN Katowice) Vol. 21, p 106

13. Białobrzeski A, Dudek P, Fajkiel A, Leśniewski W et al 2006 Arch. Foundry 697

14. Białobrzeski A, Saja K and Leśniewski W 2007 Arch. Foundry Eng. 757

15. Yan X Y, Langberg D E and Rankin W J 1995 Metall. Mater. Trans. B 261005

16. Dunn B and Farrington G C 1980 Mater. Res. Bull. 151773

17. Wen Z, Cao J, Gu Z, Xu X, Zhang F and Lin Z 2008 J. Solid State Ionics 1791697

18. Moseley P T, Bones R J, Teagle D A, Bellamy B A and Hawes R W M 1989 J. Electrochem. Soc. 1361361

19. Lu X C, Xia G G, Lemmon J P and Yang Z G 2010 J. Power Sources 1952431

20. May G J 1978 J. Power Sources 31

21. Sudworth J L 2001 J. Power Sources 100149

22. Fray D J 2003 Metall. Mater. Trans. B 34589

23. Fray D J 1977 Metall. Trans. B 8153

24. Doughty G, Fray D J, Van Der Poorten C and DeKeyser J 1996 J. Solid State Ionics 86-88 193

25. Białobrzeski A 2007 Arch. Foundry Eng. 753

26. Sigworth G K 1983 AFS Trans. 917

27. Pan E N, Cherng Y G, Lin C A and Chiou H S 1994 AFS Trans. 70609

28. Fredriksson H, Hillert M and Lange N 1973 J. Inst. Met. 101 285

29. Liu Q Y, Li Q C and Liu Q F 1991 Acta Metall. Mater. 39 2497

30. Rathoda H R and Manghani J V 2012 Int. J. Emerg. Trends Eng. Dev. 2573

31. Brown J 1999 Foseco non-ferrous Foundryman's handbook (UK: Butterworth-Heinemann) p 56

32. Mondolfo L F 1965 J. Austral. Inst. Met. 10169

33. Lu S Z and Hellawell A 1987 Metall. Mater. Trans. A 18 1721

34. Onyia C, Okorie B, Neife S and Obayi C 2013 World J. Eng. Technol. 19

35. Jian X, Meek T and Han Q 2006 Scr. Mater. 54893

36. Nafisi S and Ghomashchi R 2006 Mater. Sci. Eng. A 415273

37. Liu L, Samuel A M, Samuel F H, Doty H W and Valtierra S 2004 J. Mater. Sci. 39215

38. Zhang X H, Su G C, Ju C W, Wang W C and Yan W L 2010 Mater. Des. 314408 